\title{
Protective effects of a mineral aqueous solution on toxicity in mouse liver and kidney
}

\author{
In-Jae Park, Se-Yeoun Cha, Min Kang, Yang-Sub So, Ji-Yun Bahng, Hyung-Kwan Jang* \\ Department of Veterinary Infectious Diseases and Avian Diseases, College of Veterinary Medicine \& Korea Zoonosis Research \\ Institute, Chonbuk National University, Jeonju 561-756, Korea
}

(Received: March 27, 2013; Revised: July 31, 2013; Accepted: August 8, 2013)

\begin{abstract}
We demonstrated that a mineral aqueous solution (MAS) administered to mice functionally and histologically protected against cisplatin-induced acute renal failure (ARF) and $\mathrm{CCl}_{4}$-induced acute liver failure (ALF). In ARF model, 0.4 and $0.2 \%$ MAS decreased mortality and the serum concentrations of blood urea nitrogen (BUN) and creatine in mice. Additionally, 0.4 and $0.2 \%$ MAS reduced contraction of distal convoluted tubules and suppressed expression of the proinflammatory cytokines interlukein-6 (IL-6) and tumor necrosis factor (TNF- $\alpha$ ) in the kidney. In ALF model, 0.4 and $0.2 \%$ MAS decreased serum concentrations of alanine aminotransferase and aspartate aminotransferase in mice. Additionally, 0.4 and $0.2 \%$ MAS reduced necrotic areas and suppressed expression of IL- 6 and TNF- $\alpha$ in the liver. These results indicate that a MAS might have protective effects against ARF and ALF.
\end{abstract}

Keywords : $\mathrm{CCl}_{4}$-induced acute liver failure, cisplatin-induced acute renal failure, mineral aqueous solution, silicon

\section{Introduction}

Cisplatin and other platinum derivatives are important chemotherapeutic agents used to treat solid tumors, including ovarian, head and neck, and testicular germ cell tumors [26]. A known complication of cisplatin administration is acute renal failure (ARF). The nephrotoxic effect of cisplatin is cumulative and dose-dependent and often necessitates dose reduction or withdrawal. Approximately $25 \sim 35 \%$ of patients develop evidence of nephrotoxicity following a single dose of cisplatin [24]. Despite this toxicity, cisplatin remains one of the most commonly used chemotherapeutic drugs due to its efficacy [26].

Much attention has been focused on the direct toxic effects of cisplatin to renal tubular cells in vitro [24]. In this setting, cisplatin induces DNA damage [13, 24], mitochondrial dysfunction [31], formation of reactive oxygen species [15], caspase activation [12], and either necrotic or apoptotic cell death depending on the cisplatin concentration [14, 19]. Inflammatory mechanisms appear to play an important role in the pathogenesis of ischemic acute renal injury [4, 28].

Acute liver failure (ALF) is a rare condition consisting of rapid-onset severe liver injury accompanied by coagulopathy and encephalopathy, and a patient mortality rate of $90 \%[5$, 18]. Approximately 2,000 cases per year occur in the USA resulting in liver transplantation or death in $>35 \%$ of these cases, frequently due to multi-organ failure. Nevertheless, the etiology of ALF is mysterious in approximately $20 \%$ of adult patients in the USA [20].

Acute administration of carbon tetrachloride $\left(\mathrm{CCl}_{4}\right)$ has been used to establish an experimental model of severe hepatocellular damage involving generation of oxidative stress and recruitment of inflammatory cells [10, 21, 29], which induces liver architectural and functional damage [11, 16, 25]. Liver regeneration involves a complex regulated response to $\mathrm{CCl}_{4}$-induced ALF $[17,30]$.

Silicon is the second most abundant element in the lithosphere after oxygen and is an essential element. However, silicon has no known biochemistry to describe its requirement by biota. Although silicon is not widely regarded as an essential element in mammals, it has some beneficial actions in chicks and rats through effects on growth and skeletal development [6, 27]: abnormalities involving articular cartilage and connective tissue are produced in chicks fed a silicondeficient diet.

The objective of this study was to evaluate the protective effects of a silicon-rich mineral aqueous solution (MAS) on cisplatin-induced $\mathrm{ARF}$ and $\mathrm{CCl}_{4}$-induced ALF.

\section{Materials and Methods}

\section{MAS preparation}

The MAS was provided by Green Nanobiotech (Korea). Concentrations of nutrient constituents in the MAS such as

*Corresponding author

Tel: +82-63-270-3885, Fax: +82-63-270-2135

E-mail: hkjang@chonbuk.ac.kr 
silicon, potassium, and sodium were determined by inductively coupled plasma optical emission spectroscopy (ICP/ OES) (PerkinElmer, USA).

\section{Cisplatin-induced ARF and $\mathrm{CCl}_{4}$-induced $\mathrm{ALF}$}

Four-week-old female Balb/c mice were randomly divided into five groups $(\mathrm{n}=10)$ for the cisplatin-induced ARF study. The negative and positive control groups did not receive MAS. Three experimental groups received drinking water containing MAS $(0.4,0.2$, and $0.1 \% ; 6.24,3.12$ and $1.56 \mathrm{mg} /$ $\mathrm{kg}$ body weight as silicon concentration in MAS) for 2 weeks before cisplatin administration. Cisplatin (Sigma-Aldrich, USA) was freshly prepared in sterile normal saline at a concentration of $0.5 \mathrm{mg} / \mathrm{mL}$ the day of administration. Mice were given either $20 \mathrm{mg} / \mathrm{kg}$ body weight of cisplatin or vehicle (saline) intraperitoneally (i.p.). Kidneys were isolated and blood samples were collected via cardiac puncture on day 3 after cisplatin administration.

Four-week-old female Balb/c mice were randomly divided into five groups $(\mathrm{n}=10)$ for the $\mathrm{CCl}_{4}$-induced ALF study. The negative and positive control groups did not receive the MAS. Three experimental groups received drinking water containing MAS $(0.4,0.2$, and $0.1 \% ; 6.24,3.12$ and $1.56 \mathrm{mg} /$ $\mathrm{kg}$ body weight as silicon concentration in MAS) for 2 weeks before $\mathrm{CCl}_{4}$ administration. $\mathrm{CCl}_{4}$ (Sigma-Aldrich) was freshly prepared in olive oil at a concentration of $0.5 \%(\mathrm{v} / \mathrm{v})$ the day of administration. Mice were given either $25 \mu \mathrm{L}$ of $0.5 \%$ $\mathrm{CCl}_{4}$ or vehicle (olive oil) i.p. Livers were isolated and blood samples were collected via cardiac puncture on day 1 after $\mathrm{CCl}_{4}$ administration.

\section{Serum analysis}

Serum concentrations of blood urea nitrogen (BUN), creatine, alanine aminotransferase (ALT), and aspartate aminotransferase (AST) in mice were measured using a COBAS INTEGRA 400 plus system (Roche, Germany).

\section{Histological examination}

Kidney and liver tissues were fixed in $10 \%$ formaldehyde and embedded in paraffin, and $4-\mu \mathrm{m}$ sections were stained with hematoxylin and eosin. Histological analyses of kidney and the liver injury were performed using an Eclipse Ti-U inverted microscope (Nikon, Japan).

\footnotetext{
Quantitation of mRNA by real-time reverse-transcription polymerase chain reaction (RT-PCR)

Total RNA in kidney and liver tissues was isolated using an Easy-BLUE Total RNA Extraction kit (Intron Biotech, Korea). Real-time RT-PCR was performed with a Stratagene Mx3000P Real-Time PCR system (Stratagene, USA). Three micrograms of total RNA was reverse transcribed in a reaction volume of $20 \mu \mathrm{L}$ using GoScript Reverse Transcriptase (Promega, USA) and random primers. The product was diluted to $80 \mu \mathrm{L}$, and a $3 \mu \mathrm{L}$ aliquot was used as a template for amplification using Brilliant III Ultra-Fast SYBR Green
}

Table 1. The concentrations of essential and possible essential trace elements in the mineral aqueous solution (MAS) were measured by inductively coupled plasma optical emission spectroscopy (ICP/OES)

\begin{tabular}{cc}
\hline \hline Chemical elements & Concentration $(\%)$ \\
\hline $\mathrm{Si}$ & 26.00 \\
$\mathrm{~K}$ & 2.90 \\
$\mathrm{Na}$ & 5.36 \\
\hline
\end{tabular}

QPCR Master Mix (Agilent Technologies, USA) and genespecific primers. The primer sets used were: mouse interleukin (IL)-6 (forward: CTA TAC CAC TTC ACA AGT CGG AGG C TT; reverse: TAG GAG AGC ATT GGA AAT TGG GGT AGG), tumor necrosis factor (TNF)- $\alpha$ (forward: CAT CAG TTC TAT GGC CCA GAC CCT C; reverse: CGG CAG AGA GGA GGT TGA CTT TCT C). The amount of DNA was normalized to the GAPDH signal amplified in a separate reaction (forward: CCC CTT CAT TGA CCT CAA CTA CAT GGT; reverse: GTT GT C ATA TTT CTC GTG GTT CAC ACC C).

\section{Statistical analysis}

All data were analyzed with SPSS 12.0 statistical software (SPSS, USA). Data are expressed as mean \pm standard deviation. Statistical differences were examined independently using the Student's $t$ test and Pearson's correlation test. A $p$ value $<0.05$ was considered significant.

\section{Results}

\section{The constituents of the MAS by ICP/OES}

The concentration of essential trace elements in the MAS are listed in Table 1. Silicon was found at a high concentration $(26.0 \%)$, whereas potassium and sodium were at low concentrations (2.9 and $5.36 \%$, respectively).

\section{MAS protects mice from ARF and ALF}

We investigated the protective effects of the MAS on cisplatin-induced $\mathrm{ARF}$ and $\mathrm{CCl}_{4}$-induced ALF. The mice received drinking water or water containing the MAS $(0.4,0.2$ and $0.1 \%$ ) for 2 weeks before cisplatin and $\mathrm{CCl}_{4}$ administration.

In the cisplatin-induced ARF group, $50 \%$ of the positivecontrol group died within $72 \mathrm{~h}$, whereas only $20 \%$ of the groups receiving the MAS $(0.4$ and $0.2 \%$ ) died (data not shown). The mice were sacrificed $72 \mathrm{~h}$ after cisplatin administration for BUN and creatine determinations. At the time of killing, BUN levels in the groups receiving MAS (0.4 and $0.2 \%$ ) were significantly lower than those in the positivecontrol group $(40.9 \pm 18.67 \mathrm{mg} / \mathrm{L} v s .163 .5 \pm 45.18 \mathrm{mg} / \mathrm{L} v s$. $363.6 \pm 71.77 \mathrm{mg} / \mathrm{L}$ ) (Fig. 1A). Creatine levels in the groups receiving MAS $(0.4$ and $0.2 \%)$ were significantly lower than those in the positive-control group $(0.5 \pm 0.07 \mathrm{mg} / \mathrm{L}$ vs. $3.2 \pm$ $0.75 \mathrm{mg} / \mathrm{L}$ vs. $5.2 \pm 0.04 \mathrm{mg} / \mathrm{L}$ ) (Fig. 1B).

The mice were sacrificed $24 \mathrm{~h}$ after $\mathrm{CCl}_{4}$ administration for 

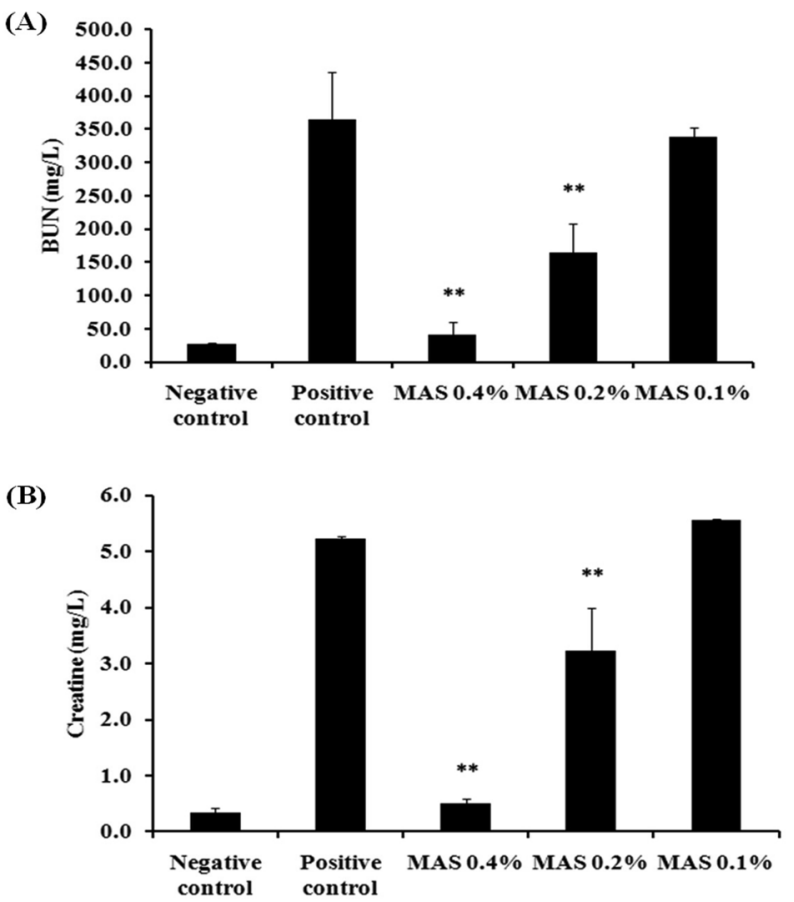

Fig. 1. Effect of the MAS on renal function in cisplatin-induced acute renal failure (ARF). Mice received drinking water or water containing the MAS $(0.4,0.2$, and $0.1 \%)$ for 2 weeks before cisplatin administration. Blood urea nitrogen (BUN) (A) and plasma creatine (B) were measured $72 \mathrm{~h}$ after cisplatin injection. Cisplatin caused severe renal dysfunction, which was partially prevented by the MAS. ${ }^{*} p<0.05,{ }^{* *} p<0.005 ; \mathrm{n}=5$.

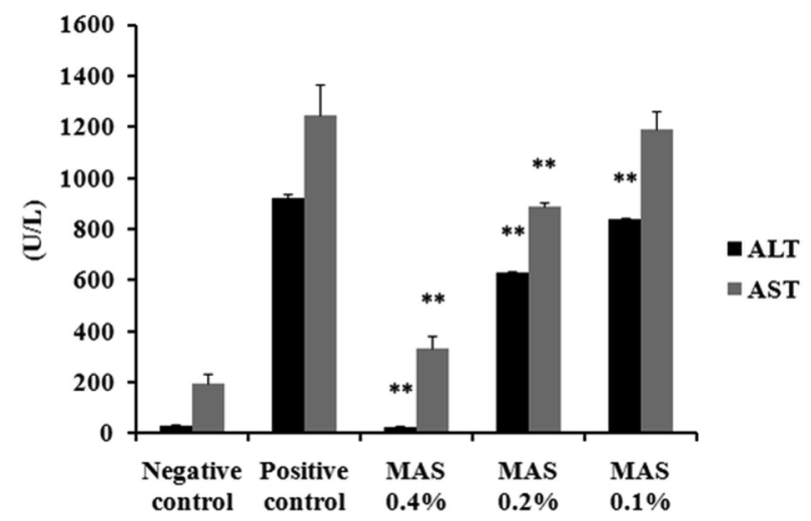

Fig. 2. Effect of the MAS on liver function in $\mathrm{CCl}_{4}$-induced acute liver failure (ALF). Mice received drinking water or water containing the MAS $(0.4,0.2$, and $0.1 \%)$ for 2 weeks before $\mathrm{CCl}_{4}$ administration. Alanine aminotransferase (ALT) and aspartate aminotransferase (AST) were measured $24 \mathrm{~h}$ after $\mathrm{CCl}_{4}$ injection. $\mathrm{CCl}_{4}$ caused severe liver dysfunction, which was partially prevented by the MAS. ${ }^{*} \mathrm{P}<0.05,{ }^{*} * \mathrm{P}<0.005 ; \mathrm{n}=5$.

ALT and AST determination in the $\mathrm{CCl}_{4}$-induced ARF group. At the time of killing, ALT levels in the groups receiving MAS $(0.4,0.2$, and $0.1 \%)$ were significantly lower than those in the positive-control group $(24.7 \pm 6.22 \mathrm{U} / \mathrm{L}$ vs. $627.4 \pm$
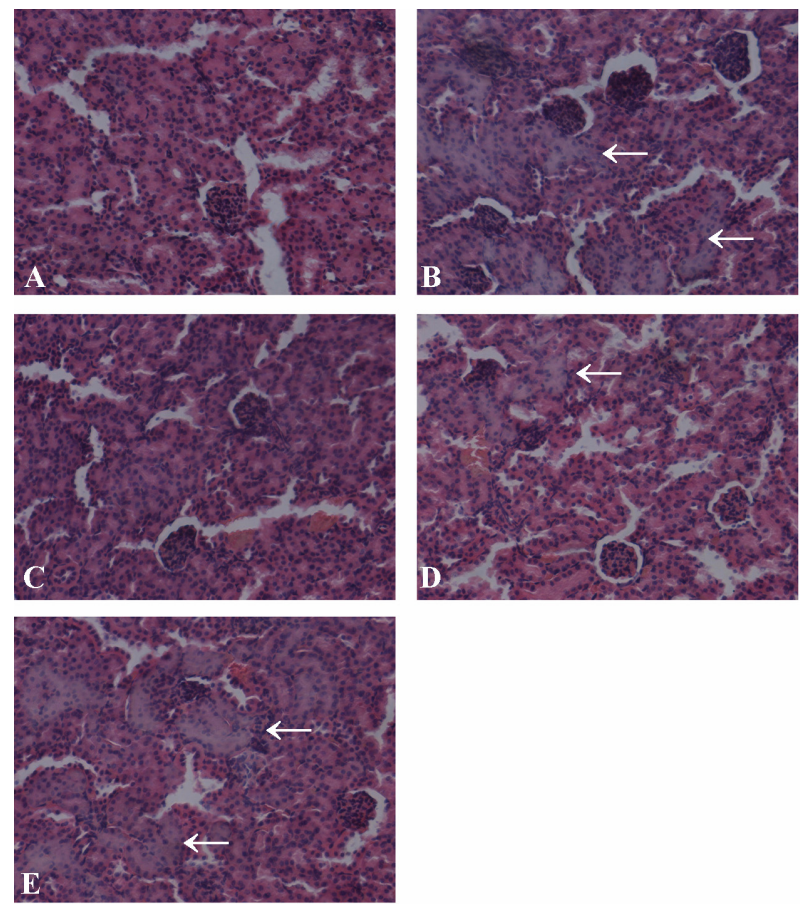

Fig. 3. Effect of the MAS on renal histology in mice. Kidney tissue was fixed in $4 \%$ paraformaldehyde at $72 \mathrm{~h}$ after cisplatin injection embedded in paraffin, cut into $4 \mu \mathrm{m}$ sections, and stained with H\&E. (A; Negative control, B; Positive control, C; $0.4 \%$ MAS, D; 0.2\% MAS, E; 0.1\% MAS). Kidney sections from the $0.4 \%$ MAS group (C) were not different with those in the negative-control (A), and the $0.2 \%$ MAS (D) showed only mild renal necrosis. arrows: necrotic areas, $\times 200$.

7.57 U/L vs. $836.8 \pm 10.15 \mathrm{U} / \mathrm{L}$ vs. $923.5 \pm 15.08$ ) (Fig. 2). AST levels in the groups receiving MAS (0.4 and $0.2 \%)$ were significantly lower than those in the positive-control group $(331.4 \pm 48.68 \mathrm{U} / \mathrm{L}$ vs. $887.4 \pm 19.31 \mathrm{U} / \mathrm{L}$ vs. $1246.9 \pm 121.44 \mathrm{U} /$ L) (Fig. 2).

\section{MAS reduces kidney and liver injury from ARF and ALF}

In cisplatin-induced ARF, kidney sections from the positive-control group showed renal necrosis at $72 \mathrm{~h}$ after cisplatin administration, whereas kidney sections from one of the groups receiving MAS (0.4\%) showed no differences with the negative-control group histology. The $0.2 \%$ MAS group showed only mild renal necrosis (Fig. 3).

In $\mathrm{CCl}_{4}$-induced ALF, liver sections from the positive-control group showed liver necrosis at day 1 after $\mathrm{CCl}_{4}$ administration, whereas liver sections from the $0.4 \%$ MAS group showed no differences with the negative control group histology. The $0.2 \%$ MAS group showed only mild renal necrosis (Fig. 4). We found that the necrotic areas diminished significantly around the central vein in the MAS groups at $24 \mathrm{~h}$.

MAS suppresses proinflammatory cytokine expression In cisplatin-induced ARF, kidneys were harvested at $72 \mathrm{~h}$ 

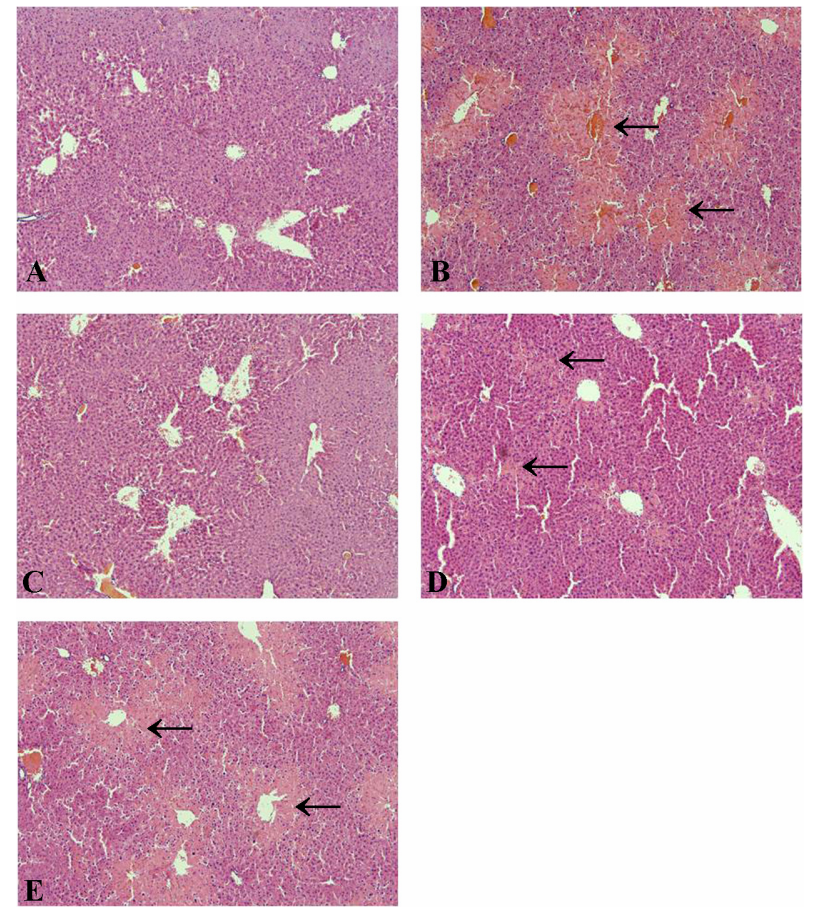

Fig. 4. Effect of the MAS on liver histology in mice. Liver tissue was fixed in $4 \%$ paraformaldehyde at $24 \mathrm{~h}$ after $\mathrm{CCl}_{4}$ injection, embedded in paraffin, cut into $4 \mu \mathrm{m}$ sections, and stained with H\&E. (A; Negative control, B; Positive control, C; $0.4 \%$ MAS, D; $0.2 \%$ MAS, E; 0.1\% MAS). Liver sections from the $0.4 \%$ MAS group $(C)$ were not different from those in the negative control (A), and the $0.2 \%$ MAS group (D) showed only mild liver necrosis. arrows: necrotic areas, $\times 40$.

after treatment with cisplatin in the negative-control, positive-control, and the MAS $(0.4,0.2$ and $0.1 \%)$ groups. In $\mathrm{CCl}_{4}$-induced ALF, livers were harvested at $24 \mathrm{~h}$ after treatment with $\mathrm{CCl}_{4}$ in the negative-control, positive-control, and the MAS $(0.4,0.2$ and $0.1 \%)$ groups. Cytokine gene expression was determined by real-time RT-PCR. IL- 6 and TNF- $\alpha$ expression in kidneys and livers of the groups receiving MAS $(0.4$ and $0.2 \%)$ were significantly lower than those in the positive-control group (Fig. 5).

\section{Discussion}

Cisplatin is an important antitumor agent used for treating various solid tumors. The key limitation of this drug is its nephrotoxicity. Studies on the pathogenesis of cisplatin nephrotoxicity have mainly focused on the direct toxicity of cisplatin in vitro, including the role of oxidative stress [1, 7]. However, recent studies have demonstrated the important role of inflammation and cytokine activity in the pathogenesis of cisplatin nephrotoxicity [8, 23].

The $\mathrm{CCl}_{4}$ model of acute intoxication has been used for decades to investigate the response to acute and chronic liver injury, because the elementary lesions caused by this hepatotoxin replicate those seen in most cases of human liver dis-

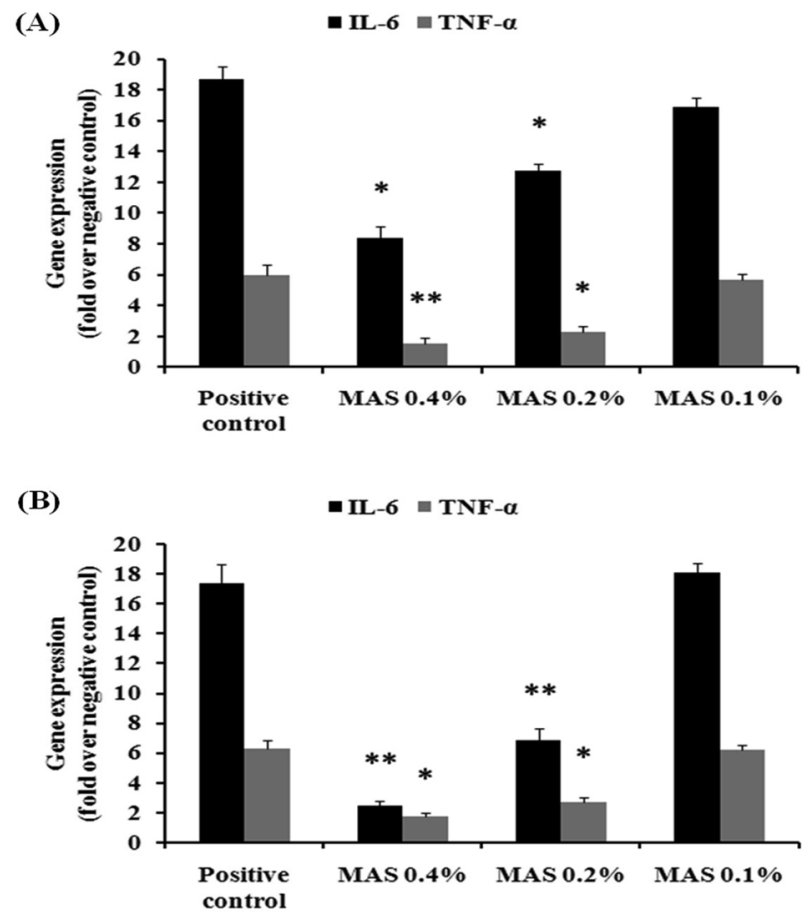

Fig. 5. Effect of the MAS on proinflammatory cytokine expression. Proinflammatory cytokine expression was determined by real-time reverse transcription polymerase chain reaction. (A; cisplatin-induced ARF, B; $\mathrm{CCl}_{4}$-induced ALF). Compared with the negative control, mice that received the MAS had reduced tumor necrosis factor (TNF)- $\alpha$ and interleukin (IL)-6 expression. ${ }^{*} p<0.05,{ }^{* *} p<0.005$.

eases. Proinflammatory cytokines are believed to play a key role in the pathogenesis of $\mathrm{CCl}_{4}$-induced liver injury $[9,17]$.

In our previous examination, we tested the protective effect of $2 \%$ MAS on cisplatin-induced $\mathrm{ARF}$ and $\mathrm{CCl}_{4}$-induced ALF. Serum BUN, creatine, ALT, and AST levels in mice that received $2 \%$ MAS were similar to those in mice that received $0.4 \%$ MAS. Additionally, the kidney and the liver histological observations in the $2 \%$ MAS - mice were similar to those in the $0.4 \%$ MAS mice. Therefore, the protective effects of $0.4,0.2$, and $0.1 \%$ MAS were examined using models of cisplatin-induced ARF and $\mathrm{CCl}_{4}$-induced ALF.

In the cisplatin-induced ARF group, serum BUN and creatine levels in the positive-control group increased dramatically compared with those in the negative control group, indicating renal dysfunction. In contrast, the 0.4 and $0.2 \%$ MAS groups showed markedly attenuated release of BUN and creatine. In the $\mathrm{CCl}_{4}$-induced ALF group, serum ALT and AST levels in the positive-control group increased dramatically compared with those in the negative-control group, indicating severe hepatocellular damage. In contrast, the 0.4 and $0.2 \%$ MAS groups showed markedly attenuated ALT and AST release.

The kidney and the liver histological observations strongly support the protective effect of the MAS on ARF and ALF (Figs. 3 and 4). Cisplatin and $\mathrm{CCl}_{4}$ caused histological changes 
in the kidney and liver, including necrosis. These alterations were significantly attenuated by the MAS, as the kidneys and the livers showed only minor necrotic areas. These results suggest that the MAS may have potential clinical applications for preventing kidney and liver disorders.

TNF- $\alpha$ and IL-6 are pleiotropic proinflammatory cytokines that are rapidly produced by macrophages in response to tissue damage $[2,32]$. While low levels of TNF- $\alpha$ may play a role in cell protection, excessive amounts cause cell impairment. An increase in TNF- $\alpha$ level has been directly correlated with histological evidence of hepatic necrosis and an increase in serum AST levels [3]. Recent studies have shown that proinflammatory cytokines such as TNF- $\alpha$ and IL-6 are associated with cisplatin-induced acute renal failure [22]. Real-time RT-PCR was performed to analyze proinflammatory cytokine levels in kidney and liver tissue. As a result, TNF- $\alpha$ and IL- 6 expression decreased in the kidneys and livers of the 0.4 and $0.2 \%$ MAS groups. These results indicate that the MAS may suppress expression of proinflammatory cytokines such as TNF- $\alpha$ and IL-6. Additional studies are required to examine this effect in further detail.

Our results provide evidence for the protective effect of the MAS in cisplatin-induced ARF and $\mathrm{CCl}_{4}$-induced ALF. Overall, the MAS not only suppressed the inflammatory response but also prevented functional damage in ARF and ALF models. Further studies will be needed to fully understand the association between the mode of action of silicon and the inflammatory responses in the protective effect of the MAS against cisplatin-induced ARF and $\mathrm{CCl}_{4}$-induced ALF.

\section{Acknowledgments}

This study was carried out with support from the "Cooperative Research Program for Agriculture Science \& Technology Development (No. PJ006336, PJ009314, PJ907105)" Rural Development Administration, and Bio-industry Technology Development Program (No. 311007-5) Ministry of Agriculture, Food and Rural Affairs, Korea.

\section{References}

1. Baliga R, Zhang Z, Baliga M, Ueda N, Shah SV. In vitro and in vivo evidence suggesting a role for iron in cisplatin-induced nephrotoxicity. Kidney Int 1998, 53, 394401.

2. Brouckaert P, Fiers W. Tumor necrosis factor and the systemic inflammatory response syndrome. Curr Top Microbiol Immunol 1996, 216, 167-187.

3. Bruccoleri A, Gallucci R, Germolec DR, Blackshear P, Simeonova P, Thurman RG, Luster MI. Induction of early-immediate genes by tumor necrosis factor $\alpha$ contribute to liver repair following chemical-induced hepatotoxicity. Hepatology 1997, 25, 133-141.

4. Burne MJ, Daniels F, El Ghandour A, Mauiyyedi S, Colvin RB, O'Donnell MP, Rabb H. Identification of the $\mathrm{CD}_{4+} \mathrm{T}$ cell as a major pathogenic factor in ischemic acute renal failure. J Clin Invest 2001, 108, 1283-1290.
5. Caraceni P, Van Thiel DH. Acute liver failure. Lancet 1995, 345, 163-169.

6. Carlisle EM. Silicon: an essential element for the chick. Science 1972, 178, 619-621.

7. Davis CA, Nick HS, Agarwal A. Manganese superoxide dismutase attenuates cisplatin-induced renal injury: importance of superoxide. J Am Soc Nephrol 2001, 12, 2683-2690.

8. Deng J, Kohda Y, Chiao H, Wang Y, Hu X, Hewitt SM, Miyaji T, McLeroy P, Nibhanupudy B, Li S, Star RA. Interleukin-10 inhibits ischemic and cisplatin-induced acute renal injury. Kidney Int 2001, 60, 2118-2128.

9. Gabay C, Smith MF Jr, Eidlen D, Arend WP. Interleukin 1 receptor antagonist (IL-1Ra) is an acute-phase protein. J Clin Invest 1997, 99, 2930-2940.

10. Johnson SJ, Hines JE, Burt AD. Macrophage and perisinusoidal cell kinetics in acute liver injury. J Pathol 1992, 166, 351-358.

11. Kalinichenko VV, Bhattacharyya D, Zhou Y, Gusarova GA, Kim W, Shin B, Costa RH. Foxf1 +/ mice exhibit defective stellate cell activation and abnormal liver regeneration following $\mathrm{CCl}_{4}$ injury. Hepatology 2003, 37, 107-117.

12. Kaushal GP, Kaushal V, Hong X, Shah SV. Role and regulation of activation of caspases in cisplatin-induced injury to renal tubular epithelial cells. Kidney Int 2001, 60, 1726-1736.

13. Leibbrandt MEI, Wolfgang GHI, Metz AL, Ozobia AA, Haskins JR. Critical subcellular targets of cisplatin and related platinum analogs in rat renal proximal tubule cells. Kidney Int 1995, 48, 761-770.

14. Lieberthal W, Triaca V, Levine J. Mechanisms of death induced by cisplatin in proximal tubular epithelial cells: apoptosis vs. necrosis. Am J Physiol 1996, 270, F700-708.

15. Matsushima H, Yonemura K, Ohishi K, Hishida A. The role of oxygen free radicals in cisplatin-induced acute renal failure in rats. J Lab Clin Med 1998, 131, 518-526.

16. Morimoto J, Yoneyama H, Shimada A, Shigihara T, Yamada S, Oikawa Y, Matsushima K, Saruta T, Narumi S. CXC chemokine ligand 10 neutralization suppresses the occurrence of diabetes in nonobese diabetic mice through enhanced $\beta$ cell proliferation without affecting insulitis. J Immunol 2004, 173, 7017-7024.

17. Morio LA, Chiu H, Sprowles KA, Zhou P, Heck DE, Gordon MK, Laskin DL. Distinct roles of tumor necrosis factor- $\alpha$ and nitric oxide in acute liver injury induced by carbon tetrachloride in mice. Toxicol Appl Pharmacol 2001, 172, 44-51.

18. O'Grady JG, Alexander GJ, Hayllar KM, Williams R. Early indicators of prognosis in fulminant hepatic failure. Gastroenterology 1989, 97, 439-445.

19. Okuda M, Masaki K, Fukatsu S, Hashimoto Y, Inui K. Role of apoptosis in cisplatin-induced toxicity in the renal epithelial cell line LLC-PK$_{1}$ : implication of the functions of apical membranes. Biochem Pharmacol 2000, 59, 195-201.

20. Ostapowicz G, Fontana RJ, Schiødt FV, Larson A, Davern TJ, Han SHB, McCashland TM, Shakil AO, Hay JE, Hynan L, Crippin JS, Blei AT, Samuel G, Reisch J, Lee WM. Results of a prospective study of acute liver failure at 17 tertiary care centers in the United States. Ann Intern Med 2002, 137, 947-954. 
21. Poli G. Liver damage due to free radicals. $\mathrm{Br}$ Med Bull 1993, 49, 604-620.

22. Ramesh G, Reeves WB. Inflammatory cytokines in acute renal failure. Kidney Int 2004, 66 (Suppl 91), S56-61.

23. Ramesh G, Reeves WB. TNF- $\alpha$ mediates chemokine and cytokine expression and renal injury in cisplatin nephrotoxicity. J Clin Invest 2002, 110, 835-842.

24. Ries F, Klastersky J. Nephrotoxicity induced by cancer chemotherapy with special emphasis on cisplatin toxicity. Am J Kidney Dis 1986, 8, 368-379.

25. Sasaki S, Yoneyama H, Suzuki K, Suriki H, Aiba T, Watanabe S, Kawauchi Y, Kawachi H, Shimizu F, Matsushima K, Asakura H, Narumi S. Blockade of CXCL10 protects mice from acute colitis and enhances crypt cell survival. Eur J Immunol 2002, 32, 3197-3205.

26. Schrier RW. Cancer therapy and renal injury. J Clin Invest 2002, 110, 743-745.

27. Schwarz K, Milne DB. Growth-promoting effects of silicon in rats. Nature 1972, 239, 333-334.

28. Sheridan AM, Bonventre JV. Cell biology and molecular mechanisms of injury in ischemic acute renal failure. Curr opin nephrol hypertens 2000, 9, 427-434.

29. Slater TF. Free-radical mechanisms in tissue injury. Biochem J 1984, 222, 1-15.

30. Steinman L, Martin R, Bernard C, Conlon P, Oksenberg JR. Multiple sclerosis: deeper understanding of its pathogenesis reveals new targets for therapy. Annu Rev Neurosci 2002, 25, 491-505.

31. Sugiyama S, Hayakawa M, Kato T, Hanaki Y, Shimizu K, Ozawa T. Adverse effects of anti-tumor drug, cisplatin, on rat kidney mitochondria: disturbances in glutathione peroxidase activity. Biochem Biophys Res Commun 1989, 159, 1121-1127.

32. Tackey E, Lipsky PE, Illei GG. Rationale for interleukin-6 blockade in systemic lupus erythematosus. Lupus 2004, 13, 339-343. 